\title{
Using Speaking Frames as Scaffolding Tools to Teach University Students to Speak in ESP
}

\author{
Nataliia Saienko \\ National Technical University of Ukraine, Igor Sikorskiy Kyiv Polytechnic \\ Institute, Kyiv, Ukraine \\ https://orcid.org/0000-0001-8898-5198 \\ Iryna Nazarenko \\ National Technical University of Ukraine, Igor Sikorskiy Kyiv Polytechnic \\ Institute, Kyiv, Ukraine \\ https:/ / orcid.org/0000-0002-7919-7939
}

\begin{abstract}
This paper deals with the issue of using speaking frames as scaffolding tools for teaching software engineering students to speak in an ESP (English for Specific Purposes) course. We believe that students' knowledge of the process of learning, and developing their metacognitive skills, may influence their learning outcomes greatly. So, in the study, we used frames as generalized scaffolds, with the idea that, by assigning meanings to objects, images and representations, we could manipulate cognitive functions, such as remembering, perceiving and concentrating, which, in turn, could influence speaking production positively. We aimed to determine the effectiveness of using frames as knowledge representation elements for improving speaking skills of software engineering students in an ESP course, as well as determining the attitudes of these students to using speaking frames for developing their speaking skills. We applied the hypothesis that the quality of students' monologues may increase considerably if they practiced using scaffolding tools such as speaking frames on a regular basis. We used a mixed research design, and combined qualitative and quantitative approaches. The qualitative approach was aimed at collecting data about students' attitudes to using speaking frames while developing professional communicative competence in spoken production. For that purpose, we used a questionnaire for students, containing open- and closed-ended questions. The quantitative approach was focused on evaluating the effectiveness of using speaking frames in experimental learning, by comparing the students' monologue speeches before and after the experimental learning using speaking frames. The study took place in 2019-2020 and involved 41 third-year students of Heat and Power engineering faculty of the National Technical University of Ukraine Igor Sikorsky Kyiv Polytechnic Institute. The results of the study show that the use of speaking frames enabled a significant increase in the number of students who demonstrated a sufficient level of speaking
\end{abstract}


competence. Using frames helped students to reduce repetitions, hesitations, false starts and pauses, and to significantly increase the number of continuous utterances while delivering monologues. The use of speaking frames contributed not only to the improvement of grammar accuracy and formation of lexical fields, but also to the structuring of students' speech.

Keywords: speaking skills; English for Specific Purposes; scaffolding; speaking frames; software engineering students

\section{Introduction}

Present-day demand for skilled and highly qualified software engineers seems to have no limit. This demand is exacerbated by the increased reliance of people around the world on IT technologies, by the rise of complex technology-driven industries and, as a result, by the need for more sophisticated technological solutions. Ukrainian software engineers are active participants in many international software engineering programs and have great potential in this field. Considering this, it has become necessary to train software engineering students at the tertiary level. Along with profound professional knowledge and skills, software engineering students have to possess an adequate English language proficiency level, as the effectiveness of their work, as well as their career development, strongly depends on their ability to analyze information in English, participate in meetings and discussions, work in international project teams, and communicate with colleagues abroad (Casañ-Pitarch et al., 2020; Mammadov et al., 2019). It should also be mentioned that software engineering students have to deal with an abundance of information, a large amount of which is in English, so they have to acquire a set of strategies for retrieving and processing information quickly and organizing it effectively. According to psychological studies of this category of students, they tend to be highly organized and responsible, have strong intrinsic motivation and cognitive abilities, possess self-directed learning skills, and have an inclination to plan and organize their activities, due to their algorithmic thinking abilities (Lytovchenko et al., 2018; Saienko, 2017; Saienko \& Lavrysh, 2020; Synekop, 2018). Therefore, there is a need for new, effective ways of improving English for Specific Purposes (ESP) teaching at the tertiary level, with particular attention paid to effective ways of structuring knowledge.

In this context, we considered the use of scaffolding techniques as means of structuring learning activities and raising the effectiveness of ESP learning. The roots of scaffolding reach as far back as the sociocultural theory of mind by Vygotsky (1986). The basic idea behind the theory is that human psychology is a fundamentally mediated activity (p. 2). Vygotsky (1986) reasoned that people tend to create symbolic tools that can contribute to their psychological movement. By assigning meanings to objects, images and, on a larger scale, representations, people are able to gain control of cognitive functions such as remembering, perceiving and concentrating. According to Wood et al. (1976), scaffolding refers to a form of just-in-time assistance that helps a student "to solve a problem which is beyond his/her unassisted efforts" (p. 90). Basically, scaffolding is identified as a means to retain the attention on the task, reduce frustration and model solutions 
(Wood et al., 1976). Scaffolding has progressed to teacher-student interaction, in which context it means the activity within teacher-student interaction that is aimed at teachers providing any kind of support to students (Gonulal \& Loewen, 2018; Lytovchenko et al., 2018), so that students do not find the task too difficult, and become able to execute it effectively. Scaffolding uses clues, hints and prompts to help students develop their ideas and see the result as the outcome of their own thoughts.

The potential of scaffolding in second-language learning has been extensively investigated. Scaffolding represents a temporary, though essential element of supportive interaction, with the help of which novices are assisted by experts, who are represented by not only teachers, but by parents, other mentors or even peers (Aljaafreh \& Lantolf, 1994). Unlike the primary meaning of scaffolding, scaffolding in education - which makes a positive contribution that has been extensively investigated (Aljaafreh \& Lantolf, 1994; Antón, 1999; Askell-Williams et al., 2011; Cudd \& Roberts, 1993; Donato \& Adair-Hauck, 1992; Hong et. al., 2011; Li, 2012; Kiewra, 2002; Panselinas \& Komis, 2009; Poehner, 2018) - is not a rigid structure, but a flexible means to support a person's self-regulated educational activity; it is a means of keeping the focus on the task, reducing frustration and modeling solutions (Wood et al., 1976). Scaffolding can be put to use in several ways with students of English language. Popular instructional scaffolding techniques include modeling, schema building, contextualizing, bridging, and text representation.

It is modelling that provides students with illustrative examples of what they are to achieve, and provides them with explicit guidance. Teachers can provide students with tasks and activities, as well as with proper language patterns, to enable vocabulary diversity while students are completing tasks and activities.

Scaffolding in language teaching is perceived as teacher-student interaction that is aimed at prompting the acquisition of target language forms (lexical items, grammatical and sentence structures, etc.). Studies within the frame of ESL classrooms report positive effects of scaffolding on students' learning of the second language. $\mathrm{Li}$ (2012) studied the use of scaffolding as facilitative assistance for dealing with English semantics while students were negotiating the meaning of unknown words. Li's study showed the positive effect of scaffolding on college students' acquisition of a second language. A recent study by Lantolf and Poehner (2014) show that the degree of explicitness of scaffolding that a student requires is an indication of how far he/she is from independent control over certain features of the language.

It should be mentioned that the basic understanding of the role of scaffolding as a supportive interaction has changed since its initial understanding by Vygotsky (1986). It has progressed to a specific teacher activity that assists students to master difficult tasks, with little respect to developmental issues (Poehner, 2018). Wells (1999) and Maybin et al. (1992) highlight the importance of scaffolding, not as a task at hand, but as a means for developing students in the first place. They point out the importance of adjusting corrective feedback in relation to change 
brought about by students' development, and recommend that flexibility should prevail over rigidity in teacher-student mediation.

Nonetheless, existing studies fail to provide sufficient evidence of the kind of collaborating mediation that could contribute to students' independent learning. In this context, individual learners' characteristics play a significant role, as learners have different backgrounds and preferences. Few empirical studies on scaffolding in teacher-student interaction have been done in Ukrainian ESP classrooms. There is, thus, a need for empirical studies on the use of scaffolding as a means that can contribute to the development of the ESP speaking competences of software engineering students.

To achieve this goal, we used speaking frames as a scaffolding tool for communication in professional software engineering. We see scaffolding as a tool that will help students to keep their focus on the task and reduce frustration. We had two considerations in developing the idea of using speaking frames for the development of the ESP speaking competences of software engineering students. Firstly, students' monologues in English often lack organization and linking structures; sometimes there are problems with vocabulary choice, or sentences are grammatically incorrect. The second consideration was that software engineering students, who have extensive analytical skills, should be able to organize their ideas, and construct a plan of what they want to say. However, quite often, they have problems with the accuracy of their presentation. With this in mind, we made an effort to give students the task to build a scaffold, so that they could concentrate on the aspect being studied (on the semantic/sentence level) and apply a generalized idea of the text structure (on the text level).

Initially, frames act as a basic skeleton that emerges in people's minds before they execute any activity. Frames are referred to as previously acquired experience, or existing knowledge of a person about an object or a process that could help them to take further decisions. The idea of frame-based systems was initiated by Minsky (1975), and elaborated further by Schank and Abelson (1977) as scriptbased systems. The key idea behind these notions is that our knowledge of concepts, events, and situations is based on our expectations of key characteristics of those concepts or events. Frames represent a core element and its peripherals. Using frames to teach speaking can be justified by their correlation with the condensed quality of inner speech (Wiley, 2016, p. 177). Inner speech violates the linguistic rules of ordinary language - it can be squeezed, sentences are fragmentary, and semantics is irregular (Wiley, 2016). Using speaking frames is a way to motivate students to keep their attention on the core element of the frame, and generalize or model the interconnection between the core element and its peripherals by applying language units and grammar structures on the topic being discussed. Modeling allows us to depict events and objects for further representation (Justi \& Gilbert, 2003). Frames are useful for accounting for generalization in spoken interaction (Fischer, 2011).

Frames as scaffolding tools were originally developed to support writing skills. Research has been done on the application of so-called sentence frames (Donnelly 
\& Roe, 2010). In their study, the researchers gave students sentence frames with the vocabulary underlined, and sentence frames with vocabulary removed. Students were provided a word bank of the target vocabulary words, and had to fill in the blanks. Support was given to students on how to select vocabulary, insert it into the frame, and read the frames aloud.

The use of speaking frames to develop speaking, listening and writing skills is described by Palmer (2010), who used scaffolding tools for children to boost their confidence in the use of language patterns. His idea was to provide students with patterns of literate talk, because, during spontaneous speech, their language patterns and vocabulary are limited and speech is fragmented, incoherent and lacking in organization. We observed similar problems in software engineering students who study English within specific professional contexts. Studies by Donnelly and Roe (2010) and Palmer (2010) were applied to teach English to English-speaking students.

The aim of this paper was to determine the effectiveness of using frames for teaching speaking skills within the ESP course to software engineering students; and to determine the attitudes of software engineering students towards using speaking frames for the development of ESP speaking competence.

\section{Methods}

\section{Research Design}

This study used a mixed research design that combined qualitative and quantitative approaches. The qualitative approach was aimed at collecting data about students' attitudes to using speaking frames while developing professional communicative competence in spoken production. For that purpose, we used a questionnaire for students that contained open- and closed-ended questions. The quantitative approach was focused on evaluating the effectiveness of using speaking frames in experimental learning, by comparing the students' monologue speeches before and after the experimental learning using speaking frames. For this part of the investigation, we used the oral testing and assessment criteria described below.

\section{Participants}

The study took place in 2019-2020 and involved 41 third-year students of Heat and Power engineering faculty at the National Technical University of Ukraine Igor Sikorsky Kyiv Polytechnic Institute, who were volunteers and could interrupt their participation in the study at any time. They were divided into two groups consisting of approximately the same numbers of students with low, sufficient and high levels of speaking skills, defined according to the criteria described in the Pearson Test of English score guide version 9 (March, 2019).

\section{Procedure and Instruments}

Over three months, we worked with two groups of students: the experimental group (20 students), which used speaking frames when preparing for monologues, and the control group (21 students), which studied without the use of frames. After the students had studied three topics (communication systems, 
programming languages, and computer software), we assessed the achievement of students in both groups according to the list of chosen criteria (which will be described below). We also asked the students of the experimental group to fill in the questionnaire by expressing their personal attitudes to the use of the speaking frames, and to explain the difficulties they experienced while planning a speech before and after using the speaking frames.

The study comprised four stages. In the first, pre-experimental stage, the students had to make up a monologue according to the suggested professional situation, so that we could determine their English language proficiency level in productive ESP speaking according to criteria that we had we selected. At this stage, students were asked to produce monologues without preparation, on professionally based topics suggested to them (each student had a separate printout with a communicative task). There were seven suggested topics, all of which were related to the students' curriculum. Students approached the teacher one by one and produced a monologue on a given topic; their speech was recorded in compliance with their prior agreement. Students were limited to speaking for two minutes while producing the monologues. The whole procedure of the first stage, for the two groups to produce the pre-experiment monologues, took four lessons.

We grounded our evaluation on the list of criteria described in the Pearson Test of English score guide version 9 (March, 2019). The students' monologues were evaluated according to the following five criteria: native-like (the student was given 5 points if his/her speech flowed smoothly, there were no repetitions, hesitations, and false starts or non-native phonological simplifications); advanced (the student was given 4 points if his/her speech had an acceptable rhythm, with appropriate phrasing and word stresses, no more than one hesitation, repetition or a false start, and there were no significant non-native phonological simplifications); good (the student was given 3 points if his/her speech was at an acceptable speed, but might have been uneven or there were more than one hesitation, repetition or false start, yet most words were spoken in continuous phrases, there were no long pauses and speech didn't sound staccato); intermediate (the student was given 2 points if his/her speech was uneven or staccato, had at least one smooth three-word run and no more than two or three hesitations, repetitions or false starts); or limited (the student was given 1 point if his/her speech phrasing or the sentence rhythm was irregular, the phrasing was poor, contained multiple repetitions, hesitations, or false starts, spoken performance was rather rough, the speech contained long pauses, and sentence-level word stress was inappropriate) (p. 62).

In the second stage, the students were taught English monologue speech with the use of speaking frames as a scaffolding tool. Before it is produced orally, any utterance is pre-planned and formed in inner speech; inner speech precedes the phase of speech production, and a person constructs inner contracted utterances before their production. Thus, inner speech is condensed and always precedes the actual speech. Because inner speech is difficult to observe, we would find it difficult to understand content if we structured it exactly as we experience it 
(Wiley, 2016, p. 11). As pointed out by Vygotsky (1986), inner speech represents a private language that only an individual speaker can understand.

We applied speaking frames at two levels, at sentence level and at text level. At the sentence level, we used speaking frames to practice using grammatical structures, to learn the terminology of a topic or a set of topics by organizing the terms in semantic fields (picturing them as mind maps, schemes etc.), and find synonyms or opposites, and so on. Students worked in groups, which provided peer assessment as well as teacher assessment. Students had to use the assessment criteria to evaluate their peers' achievements in the use of language and grammar. At the text level, students had to listen to or read the whole monologue as an ideal speech sample, seize the main ideas and then construct its speaking frame themselves. At this stage, they generalized ideas and drew a scheme of the monologue. Doing so was very helpful, as they paid greater attention to how the sample monologues were organized and what key elements made for a wellstructured monologue.

The second stage took six lessons, during which each student produced a monologue on the professional topic using speaking frames as scaffolding tools. This stage had the aim of providing opportunity for practice. The monologues were not recorded. Different types of the tasks were given to students, depending on the level at which the task was introduced. At the text level, we required students to construct frames based on the main idea of the text they had read. Then, we analyzed the text and discussed it at the sentence level, in order to focus the students' attention on language units or grammatical structures. Finally, students had to produce their own texts by drawing their own frames for the ideas to be presented. Different kinds of scaffolds were produced by students, or generalized during group discussions.

A study by Donato and Adair-Hauck (1992) revealed the potential of coconstructing scaffolds in students' peer-to-peer interaction during teaching of a second language to beginner-level university students. We fully support the idea that students should not be limited to the role of receivers in the process of constructing scaffolds and, in our study, we suggested that students feel free and were creative in constructing their own speaking frames (at both the sentence and text levels), and that they made use of self-assessment and peer-assessment lists. Students could share their speaking frames with peers, if they wished.

In the third stage, we tested both the experimental and the control groups after the experimental studying. After studying the same topics, students of both groups had to make up monologues for a suggested situation. Their monologues were recorded and assessed according to the same list of criteria that was used at the first, pre-experimental, stage described above.

After this, the coefficient of effectiveness of learning according to Fisher (1992) was defined. The post-experimental results of the control group and the experimental group were compared. The coefficient of effectiveness of learning was defined according to the following formula: 


$$
\varphi^{*}=\left(\varphi_{1}-\varphi_{2}\right) \cdot \sqrt{\frac{n_{1} \cdot n_{2}}{n_{1}+n_{2}}}
$$

In the fourth stage, a questionnaire was used to investigate the students' attitudes towards using speaking frames as scaffolding tools for improving their ESP speaking skills (monologue speech). It took students 10-15 minutes to complete the questionnaire. Students had to answer open- and closed-ended questions, six in total. The questionnaire aimed to find out if students experienced difficulties structuring the monologue speech, what tools they usually used to plan a speech, if schematically represented information simplified their perception and helped the production, if speaking frames helped them to organize their speech, what kind of speaking frame they preferred, what other tools could assist them in producing monologues, and if they liked using speaking frames to prepare monologues. The students' participation in the experimental learning was voluntary.

\section{Results}

This study aimed to evaluate the effectiveness of using speaking frames in teaching speaking skills to ESP classes, and used qualitative and quantitative research approaches. We defined the level of speaking skills in monologue speech as low if a student's monologue presentation was limited according to the previously mentioned criteria, sufficient if the level of presentation was valued as intermediate or good, and high if it corresponded with the native-like or advanced level. Data obtained from the results of the oral testing shows that, at the beginning of the experiment, the levels of ESP speaking skills in the control and experimental groups were almost the same. After the experimental learning, students of the experimental group showed significantly better results in producing monologues than students in the control group. The overall results are summarized in Table 1.

Table 1. Quantitative analysis of the effectiveness of using frames to teach ESP speaking skills

\begin{tabular}{|c|c|c|c|c|}
\hline \multirow[b]{2}{*}{$\begin{array}{l}\text { Levels of speaking } \\
\text { skills } \\
\text { (monologue speech) }\end{array}$} & \multicolumn{2}{|c|}{ Control group } & \multicolumn{2}{|c|}{ Experimental group } \\
\hline & $\begin{array}{l}\text { Number } \\
\text { of students } \\
\text { (total 21) }\end{array}$ & $\%$ & $\begin{array}{c}\text { Number } \\
\text { of students } \\
\text { (total 20) }\end{array}$ & $\%$ \\
\hline \multicolumn{5}{|c|}{ Before the use of speaking frames } \\
\hline Low & 9 & $43 \%$ & 8 & $40 \%$ \\
\hline Sufficient & 8 & $38 \%$ & 7 & $35 \%$ \\
\hline High & 4 & $19 \%$ & 5 & $25 \%$ \\
\hline \multicolumn{5}{|c|}{ After the use of speaking frames } \\
\hline Low & 7 & $33 \%$ & 0 & $0 \%$ \\
\hline Sufficient & 9 & $43 \%$ & 14 & $70 \%$ \\
\hline High & 5 & $24 \%$ & 6 & $30 \%$ \\
\hline
\end{tabular}

As can be seen in Table 1, none of the students of the experimental group scored a low level of speaking competence after the experimental learning, while, in the control group, there were $7(33 \%)$ such students. The use of speaking frames 
significantly increased the number of students who performed at a sufficient level of speaking competence (monologue speech) in the experimental group, compared to the control group (14 (70\%) vs $9(43 \%)$, respectively.

A high level of English speaking competence in monologue speech after the completion of the experiment was achieved by $6(30 \%)$ students of the experimental group and $5(24 \%)$ students of the control group. Thus, the results of the experiment indicate better dynamics in the development of ESP speaking skills in the experimental group than in the control group, which suggests that using speaking frames to teach monologue speech to software engineering students is effective and feasible.

To assess monologue speech, we analyzed the monologues according to the criteria and calculated the number of hesitations, repetitions and false starts and the number of pauses in monologues delivered before and after the experimental learning of the experimental group. The results are shown in Table 2.

Table 2. Quantitative analysis of the total number of speech violations of students before and after the experimental learning

\begin{tabular}{|l|c|c|c|}
\hline Criterion element & $\begin{array}{c}\text { Before the } \\
\text { experiment }\end{array}$ & $\begin{array}{c}\text { After the } \\
\text { experimental } \\
\text { learning (using } \\
\text { speaking frames) }\end{array}$ & $\begin{array}{c}\text { Difference } \\
\text { (+/-) }\end{array}$ \\
\hline Hesitations & 25 & 11 & -14 \\
\hline Repetitions & 23 & 13 & -10 \\
\hline False starts & 16 & 5 & -11 \\
\hline Pauses & 18 & 6 & -12 \\
\hline $\begin{array}{l}\text { Number of continuous } \\
\text { utterances }\end{array}$ & 24 & 58 & +34 \\
\hline $\begin{array}{l}\text { Number of staccato } \\
\text { utterances }\end{array}$ & 19 & 9 & -10 \\
\hline
\end{tabular}

As we can see in Table 2, the use of speaking frames enabled students to reduce the number of hesitations from 25 to $11(-14)$ and repetitions from 23 to $13(-10)$, and significantly reduce the number of false starts (from 16 to $5(-11))$ and pauses (from 18 to $5(-12)$ ). Moreover, the experimental learning enabled students to create more continuous utterances (increased from 24 to $58(+34)$ ) and reduced the number of staccato utterances (from 19 to $9(-10)$ ). The data in Table 2 shows that the use of speaking frames as scaffolding tools may contribute considerably to the development of the speaking competence of software engineering students.

We believe that achieving the learning outcome implies that the student has achieved a sufficient or high level of speaking skills. Failing to achieve the learning outcome implies that the student has a low level of speaking skills, determined in accordance with the criteria described in Pearson Test of English score guide version 9 (March, 2019). Table 3 represents the quantitative comparison of the number of students who achieved and failed to achieve the outcomes in the control and experimental groups. 
Table 3. Quantitative analysis of achieving or failing to achieve the learning outcomes in control and experimental groups

\begin{tabular}{|l|c|c|c|c|c|}
\hline \multirow{2}{*}{ Group } & \multicolumn{2}{|c|}{$\begin{array}{c}\text { Achieved learning } \\
\text { outcome }\end{array}$} & \multicolumn{2}{c|}{$\begin{array}{c}\text { Failed to achieve learning } \\
\text { outcome (low level of } \\
\text { speaking skills) }\end{array}$} & \multirow{2}{*}{ Sum } \\
\cline { 2 - 5 } & $\begin{array}{c}\text { Number of } \\
\text { students }\end{array}$ & $\begin{array}{c}\% \\
\text { (percentage) }\end{array}$ & $\begin{array}{c}\text { Number of } \\
\text { students }\end{array}$ & $\begin{array}{c}\% \\
\text { (percentage) }\end{array}$ & \\
\hline $\begin{array}{l}\text { Experimental } \\
\text { group }\end{array}$ & 20 & $100 \%$ & 0 & $0 \%$ & 20 \\
\hline $\begin{array}{l}\text { Control } \\
\text { group }\end{array}$ & 14 & $67 \%$ & 7 & $33 \%$ & 21 \\
\hline Total number & 34 & & 7 & & 41 \\
\hline
\end{tabular}

The results were evaluated with the use of Fisher's (1992) statistical method to establish if the number of students who achieved the learning outcomes in the experimental group was significantly bigger than the number of students with a low level of speaking skills in the control group.

We defined the coefficient $\varphi_{1}$ and $\varphi_{2}$ for the experimental and control groups, respectively.

$\varphi_{1}(100 \%)=3.142$

$\varphi_{2}(67 \%)=1.918$

Then, we calculated empirical value of $\varphi^{*}{ }_{\text {emp. }}$ according to the formula:

which produced

$$
\varphi^{*}=\left(\varphi_{1}-\varphi_{2}\right) \cdot \sqrt{\frac{n_{1} \cdot n_{2}}{n_{1}+n_{2}}}
$$

$$
\varphi^{*}{ }_{\text {emp. }}=(3.142-1.918) \cdot \sqrt{\frac{20 \cdot 21}{20+21}}=1.224 \cdot \sqrt{\frac{420}{41}}=3.91
$$

The obtained empirical value of $\varphi^{*}$ (3.91) is greater than the critical value of $\varphi$ * (2.31): $\varphi^{*}$ emp. (3.91)> $\varphi^{*}$ cr (2.31). Thus, it is in the significance zone, which means that the percentage of individuals who achieved a sufficient increase in the level of the learning coefficient of monologue speech in the experimental group is greater than in the control group.

The next stage of the experiment was aimed at finding out students' attitudes towards using speaking frames as scaffolding tools for creating monologues, and used a qualitative approach. The results of the questionnaire are presented in Table 4. 
Table 4. Students' attitudes towards using speaking frames as scaffolding tools for monologue speech

\begin{tabular}{|c|c|c|}
\hline Questions & Answers & $\begin{array}{l}\text { Percentage } \\
\text { of students }\end{array}$ \\
\hline \multirow{3}{*}{$\begin{array}{l}\text { 1. Did you have any difficulties in } \\
\text { structuring your monologue speech } \\
\text { before the experimental learning? }\end{array}$} & Yes & $54 \%$ \\
\hline & $\mathrm{No}$ & $34 \%$ \\
\hline & It is difficult to say & $12 \%$ \\
\hline \multirow{4}{*}{$\begin{array}{l}\text { 2. Before the experimental learning, } \\
\text { while getting ready for a monologue } \\
\text { what did you tend to use for } \\
\text { structuring your speech? }\end{array}$} & A plan & $33 \%$ \\
\hline & A scheme & $12 \%$ \\
\hline & Keywords & $21 \%$ \\
\hline & Nothing & $34 \%$ \\
\hline \multirow{3}{*}{$\begin{array}{l}\text { 3. Did speaking frames help you in } \\
\text { production of monologues? }\end{array}$} & Yes & $89 \%$ \\
\hline & $\mathrm{No}$ & $9 \%$ \\
\hline & It is difficult to say & $2 \%$ \\
\hline \multirow{3}{*}{$\begin{array}{l}\text { 4. Did you like the experience of } \\
\text { generalizing your ideas using } \\
\text { speaking frames as scaffolding tools? }\end{array}$} & I liked it & $76 \%$ \\
\hline & I found it acceptable & $12 \%$ \\
\hline & $\begin{array}{l}\text { I would rather consider } \\
\text { different scaffolding tools }\end{array}$ & $12 \%$ \\
\hline \multirow{3}{*}{$\begin{array}{l}\text { 5. What role did speaking frames play } \\
\text { in your preparation to speaking? }\end{array}$} & Generally positive & $100 \%$ \\
\hline & Generally negative & $0 \%$ \\
\hline & No difference & $0 \%$ \\
\hline \multirow[t]{8}{*}{$\begin{array}{l}\text { 6. What were speaking frames mostly } \\
\text { helpful for? } \\
\text { (mark the points that are true for you) }\end{array}$} & $\begin{array}{l}\text { They provided a foothold for } \\
\text { a monologue thus facilitating } \\
\text { task initiation }\end{array}$ & $57 \%$ \\
\hline & $\begin{array}{l}\text { They helped to concentrate on } \\
\text { the topic }\end{array}$ & $65 \%$ \\
\hline & $\begin{array}{l}\text { They assisted in structuring } \\
\text { the ideas }\end{array}$ & $61 \%$ \\
\hline & $\begin{array}{l}\text { They supplied with } \\
\text { additional constructions for } \\
\text { linking the ideas }\end{array}$ & $53 \%$ \\
\hline & $\begin{array}{l}\text { They allowed grounding the } \\
\text { arguments in a variety of } \\
\text { ways }\end{array}$ & $47 \%$ \\
\hline & $\begin{array}{l}\text { They provided with different } \\
\text { ways to conclude a } \\
\text { monologue }\end{array}$ & $65 \%$ \\
\hline & $\begin{array}{l}\text { They allowed raising self- } \\
\text { confidence while presenting a } \\
\text { monologue }\end{array}$ & $72 \%$ \\
\hline & $\begin{array}{l}\text { They ensured stress reduction } \\
\text { during the classroom learning }\end{array}$ & $81 \%$ \\
\hline \multirow{3}{*}{$\begin{array}{l}\text { 7. Would you like to use speaking } \\
\text { frames in further studies? }\end{array}$} & Yes & $83 \%$ \\
\hline & No & $8 \%$ \\
\hline & $\begin{array}{l}\text { Own answers: } \\
\text { (I would use this approach for } \\
\text { studying other disciplines; it } \\
\text { was helpful, but now I know } \\
\text { how to do it, etc.) }\end{array}$ & $9 \%$ \\
\hline
\end{tabular}


The results of the questionnaire show that $54 \%$ of students experienced difficulties in structuring their monologue speech, while $89 \%$ stated that schematically representing information simplified their perception and helped the production of the monologues. Before the experimental learning, while they were getting ready to present monologues, these students mostly used a plan (33\%), a scheme $(12 \%)$, keywords $(21 \%)$ or nothing $(34 \%)$ to help structure their speech. Most students $(76 \%)$ agreed that the use of frames as scaffolding tools during the experimental learning helped them to organize their monologue speeches. All the students agreed about the positive role of speaking frames in preparing to speak. The majority of students (76\%) liked the experience of generalizing their ideas using speaking frames to prepare a monologue, $12 \%$ found it acceptable, and $12 \%$ of students would rather consider different scaffolding tools. As can be seen in Table 4, students acknowledged that speaking frames provided them with a foothold for their monologues and facilitated task initiation (57\%); enabled different ways to conclude a monologue (65\%); assisted in structuring their ideas (61\%); supplied additional constructions for linking ideas (53\%) and enabled them to ground their arguments in a variety of ways (47\%). Moreover, students acknowledged the positive effect of using speaking frames as scaffolding tools for stress reduction during classroom learning $(81 \%)$ and improving self-confidence while presenting monologues $(72 \%)$. The majority of students, $83 \%$, would like to use speaking frames in further studies, whereas only $8 \%$ would not. Some students $(9 \%)$ acknowledged that they would consider applying this approach to study other disciplines, or that they had already mastered this scaffolding tool.

Thus, in summarizing the results, we can conclude that speaking frames can be considered as effective scaffolding tools for teaching ESP speaking to software engineering students. The quantitative approach allowed us to see better dynamics in the development of ESP speaking skills in the experimental group, than in the control group, whereas the qualitative approach exposed mostly positive attitudes in students in relation to using such scaffolding tools while mastering ESP speaking.

\section{Discussion}

The results of our study, which was dedicated to the use of frames for teaching ESP to software engineering students, show that, when delivering monologues, students experience difficulties in structuring the speech. In this context, particular attention was paid to a scaffolding technique, namely speaking frames. We agree with Gilbert and Justi (2016) that modelling appears to be a core process in all human thinking, and that we should not underestimate its value for education. We intended to apply scaffolding techniques that would allow IT students to activate their thinking while they were creating monologues by modeling the whole structure of the monologue in terms of its lexical and grammatical aspects. In support of Mayer's (1998) idea of three broad factors of influence on learning, namely motivation (will), cognition (skill) and metacognition (metaskill), our study found that metaskills could contribute greatly to the language learning process. Based on our findings, we also agree with other researchers (Askell-Williams et al., 2012; Winne \& Hadwin, 1998), who argue that, if students are to master some domain, they use prior knowledge from 
two domains: the subject-matter domain, and the domain of knowledge about how to go about learning itself (Winne \& Hadwin, 1998). Consistent with studies that focused on positive learning environments (e.g., Lavrysh et al., 2020), we may conclude that linguistic support of students (use of scaffolding tools) contributed to the provision of psychological support and a friendly learning community, in which students could learn from one another and share their ideas.

Thus, we chose frames to model the aspect being studied, or the situation of professional conversation of a software engineering specialist as scaffolding units, with the initial understanding of frames as being organized packages of knowledge, beliefs, and patterns of practice that shape and enable people to make sense of their experiences (Gonulal \& Loewen, 2018). The definition of frames also defines the way a person perceives and remembers information, because, by assigning meanings to objects, images and representations, we can manipulate cognitive functions such as remembering, perceiving and concentrating. So, by practicing speaking frames in the form of generalized scaffolds for further monologue presentation, students, to some extent, imitate a natural speech production process and gain confidence in speaking.

The experiment confirms the effectiveness of the use of such scaffolding tools as speaking frames for raising students' English speaking competence. It enabled improving student's monologue presentation skills, by providing a foothold for monologues by facilitating task initiation, helping the speaker to concentrate on the topic, assisting with structuring ideas, supplying additional linking constructions, providing different ideas for grounding the arguments, and concluding monologues.

Though the study was aimed at contributing to the development of software engineering students' speaking competence, we also highlighted the positive functional role of frames as a scaffolding technique that can change the learning outcome. The experimental group showed that it is possible to significantly improve both speaking production and metaskills such as concentration, information structuring and remembering.

Similar research was done by Afitska (2015), who conducted a study on the development of materials to provide support to students learning science and language, whose native language was not English. The researcher introduced speaking frames as scaffolds at both discourse and lexical levels. Gap-filling tasks were introduced to help students concentrate on vocabulary and cohesion. Diagram-labelling tasks were focused on vocabulary. Chart-filling tasks drew attention to discourse structure. The researcher highlighted two major targets: in particular, to provide support for target language development and to assist in subject knowledge development. The author points out that this structural organization allowed students to choose from familiar linguistic structures, or to apply the more sophisticated structures provided.

We share the views of Afitska (2015) about the necessity of using speaking frames as scaffolding tools for second-language learners, and agree that such techniques 
are valuable only if they are implemented systematically, on a regular basis. Unlike the study of Afitska (2015), we offer speaking frames as more generalized ideas, to be implemented in students' routine tasks in class as preparation for and/or presentation of monologues in English, taking into consideration the basic element of a frame - a core (a topic/situation for speaking activity) around which any set of language units and structures can be organized. At lower levels, the number of terms provided was bigger and students had more options.

In a similar way, we found the process of creating and then applying frames as means of scaffolding in speaking practice to be important, specifically for software engineering students, who generally possess high analytical problem-solving skills (Graziotin et al., 2014) and the natural ability to structure, generalize and classify knowledge. Taking into consideration the improved quality of monologues after the experimental studying, we may assume that speaking frames, as a typical form or pattern of the speech constructed in students' minds, played a decisive role in this improvement. Thus, the results of our study can be of use in teaching speaking skills to software engineering students in the ESP classroom. They may provide a foothold for monologues, facilitate task initiation, and help students to concentrate on the topic, assist in structuring ideas, and supply additional constructions; thus, widening students' lexicon usage.

\section{Conclusions}

We found the developmental value of the use of speaking frames as scaffolding tools quite significant. Firstly, our study found that speaking frames may contribute greatly to software engineers' English speaking competence. The study found that software engineering students do have a tendency to plan and organize their speech, and that schematically organizing material makes it easier for them to formulate a future utterance in English. Using frames enabled them to reduce repetitions, hesitations, false starts, pauses and the number of staccato utterances. At the same time, the number of continuous utterances significantly increased. The use of speaking frames contributed not only to the improvement of grammar accuracy and formation of lexical fields, but also to the structuring of students' speech. An important characteristic of scaffolding is the shifting of responsibility from a teacher to a student. Speaking frames are flexible means of scaffolding, because students quite quickly get used to creating them in their minds before speaking, which results in more productive monologues. We believe that teachers should not underestimate the functional value of learning strategies, in general, and modelling, in particular, as it may lead to better results for students mastering English. The results of our study can be of use for teaching ESP to software engineering students. However, it has certain limitations, since it was conducted at only one technical university and among students of only one specialty, which means generalizing results is not possible, and that further studies in other academic and national contexts are needed. 


\section{References}

Afitska, O. (2015). Scaffolding learning: developing materials to support the learning of science and language by non-native English-speaking students. Innovation in Language Learning and Teaching, 10(2), 75-89. https:// doi.org/10.1080/17501229.2015.1090993

Aljaafreh, A., \& Lantolf, J. P. (1994). Negative feedback as regulation and second language learning in the zone of proximal development. The Modern Language Journal, 78(4), 465-483. https://doi.org/10.1111/j.1540-4781.1994.tb02064

Antón, M. (1999). The discourse of a learner centered classroom: sociocultural perspectives on teacher learner interaction in the second language classroom. The Modern Language Journal, 83(3), 303-318. https://doi.org/10.1111/0026-7902.00024

Askell-Williams, H., Lawson, M. J., \& Skrzypiec, G. (2011). Scaffolding cognitive and metacognitive strategy instruction in regular class lessons. Instructional Science, 40(2), 413-443. https:// doi.org/10.1007/s11251-011-9182-5

Askell-Williams, H., Lawson, M. J., \& Skrzypiec, G. (2012). Cognitive and Metacognitive Strategies Questionnaire. PsycTESTS Dataset. https://doi.org/10.1037/t39555000

Casañ-Pitarch, R., Candel-Mora, M., Carrió-Pastor, M., Demydenko, O., \& Tikan, I. (2020). Enhancing language and cross-cultural competence through telecollaboration. Advanced Education, 7(16), 78-87. https://doi.org/10.20535/2410-8286.214539

Cudd, E., \& Roberts, L. (1993). A scaffolding technique to develop sentence sense and vocabulary. The Reading Teacher, 47(4), 346-349. http://www.jstor.org/stable/20201260

Donato, R., \& Adair-Hauck, B. (1992). Discourse perspectives on formal instruction. Language Awareness, 1(2), 73-89. https://doi.org/10.1080/09658416.1992.9959807

Donnelly, W. B., \& Roe, C. J. (2010). Using sentence frames to develop academic vocabulary for English learners. The Reading Teacher, 64(2), 131-136. https://doi.org/10.1598/rt.64.2.5

Fischer, K. (2011). Beyond the sentence: Constructions, frames and spoken interaction. Grammar and Interaction, 2(2), 185-207. https://doi.org/10.1075/cf.2.2.03fis

Fisher, R.A. (1992). Statistical methods for research workers. In S. Kotz, \& N. L. Johnson (Eds.), Breakthroughs in statistics (pp. 66-70). Springer Series in Statistics (Perspectives in Statistics). Springer. https://doi.org/10.1007/978-1-4612-43809_6

Gilbert, J., \& Justi, R. (2016). Modelling-based teaching in science education. Springer International Publishing. https://doi.org/10.1007/978-3-319-29039-3.

Gonulal, T., \& Loewen, S. (2018). Scaffolding technique. In J. I. Liontas \& TESOL International Association (Eds.), The TESOL encyclopedia of English language teaching (pp. 1-5). John Wiley \& Sons. https://doi.org/10.1002/9781118784235.eelt0180

Graziotin, D., Wang, X., \& Abrahamsson, P. (2014). Happy software developers solve problems better: psychological measurements in empirical software engineering. PeerJ, 2, e289. https://doi.org/10.7717/ peerj.289

Hong, L., Wei, Y., Guanghua, W., \& Wanxia, C. (2011). Scaffolding in teacher-student interaction: A case study in two oral English classes in China. Chinese Journal of Applied Linguistics, 34(3). https:// doi.org/10.1515/cjal.2011.026

Justi, R., \& Gilbert, J. K. (2003). Teachers' views on the nature of models. International Journal of Science Education, 25(11), 1369-1386. https://doi.org/10.1080/0950069032000070324 
Kiewra, K. A. (2002). How classroom teachers can help students learn and teach them how to learn. Theory Into Practice, 41(2), 71-80. https://doi.org/10.1207/s15430421tip4102_3

Lantolf, J. P., \& Poehner, M. E. (2014). Sociocultural theory and the pedagogical imperative in L2 education. Vygotskian praxis and the research/practice divide. Routledge.

Lavrysh, Y., Lytovchenko, I., \& Lukianenko, V. (2020). Ecocomposition integration into ESP course for Bachelors at a technical university. The MEXTESOL Journal, 44(1), 1-16. http:/ / mextesol.net/journal/index.php?page=journal\&id_article=17045

Li, D. (2012). Scaffolding adult learners of English in learning target form in a Hong Kong EFL university classroom. Innovation in Language Learning and Teaching, 6(2), 127144. https:// doi.org/10.1080/17501229.2011.626858

Lytovchenko, I., Ogienko, O., Sbruieva, A., \& Sotska, H. (2018). Teaching English for Specific Purposes to adult learners at university: methods that work. Advanced Education, 5(10), 69-75. http://dx.doi.org/10.20535/2410-8286.149741

Mammadov, N., Sokolova, S., \& Kholiavko, N. (2019). Development of students' foreign language communicative competence in context of internationalisation and informatisation of higher education. Advanced Education, 6(11), 22-29. https:// doi.org/10.20535/2410-8286.155501

Mayer, R. E. (1998). Cognitive, metacognitive, and motivational aspects of problem solving. Instructional Science, 26, 49-63. https:// doi.org/10.1023/A:1003088013286

Maybin, J., Mercer, N., \& Stierer, B. (1992). 'Scaffolding': Learning in the classroom. In K. Norman (Ed.), Thinking voices: The work of the National Oracy Project (pp. 186-195). Hodder \& Stoughton.

Minsky, M. (1988). A framework for representing knowledge. In A. Collins, \& E. E. Smith (Eds.), Readings in cognitive science. A perspective from psychology and artificial intelligence (pp. 156-189). Elsevier. https://doi.org/10.1016/b978-1-4832-14467.50018-2

Palmer, S. (2010). Speaking frames: How to teach talk for writing: Ages 10-14. Routledge. https://doi.org/10.4324/9780203846360

Panselinas, G., \& Komis, V. (2009). "Scaffolding" through talk in groupwork learning. Thinking Skills and Creativity, 4(2), 86-103. https:// doi.org/10.1016/j.tsc.2009.06.002

Poehner, M. E. (2018). Scaffolding and the development of L2 grammar. In J. I. Liontas \& TESOL International Association (Eds.), The TESOL encyclopedia of English language teaching. John Wiley \& Sons. https://doi.org/10.1002/9781118784235.eelt0098

Saienko, N. (2017). Cognitive development of students in foreign language acquisition. Advanced Education, 3(7), 4-8. https://doi.org/10.20535/2410-8286.77570

Saienko, N., \& Lavrysh, Y. (2020). Mobile assisted learning for self-directed learning development at technical university: SWOT analysis. Universal Journal of Educational Research, 8(4), 1466-1474. https://doi.org/10.13189/ujer.2020.080440

Synekop, O. (2018). Cognitive aspect of learning style in differentiated ESP instruction for the future IT specialists. Advanced Education, 5(10), 40-47. https:// doi.org/10.20535/2410-8286.151271

Schank, R., \& Abelson, C. (1977). Scripts, plans, goals, and understanding. An inquiry into human knowledge structures. Lawrence Erlbaum Associates.

Vygotsky, L. S. (1986). Thought and language. MIT Press.

Wells, G. (1999). Dialogic inquiry: Toward a sociocultural practice and theory of education. Cambridge University Press. 
Wiley, N. (2016). Inner speech and the dialogical self. Temple University Press. https:// doi.org/10.2307/j.ctvrf897g

Winne, P. H., \& Hadwin, A. F. (1998). Studying as self-regulated learning. In D. J. Hacker, J. Dunlosky, \& A. C. Graesser (Eds.), Metacognition in educational theory and practice (pp. 277-304). Erlbaum.

Wood, D., Bruner, J. S., \& Ross, G. (1976). The role of tutoring in problem solving. Journal of Child Psychology and Psychiatry, 17(2), 89-100. https://doi.org/10.1111/j.14697610.1976.tb00381.x 